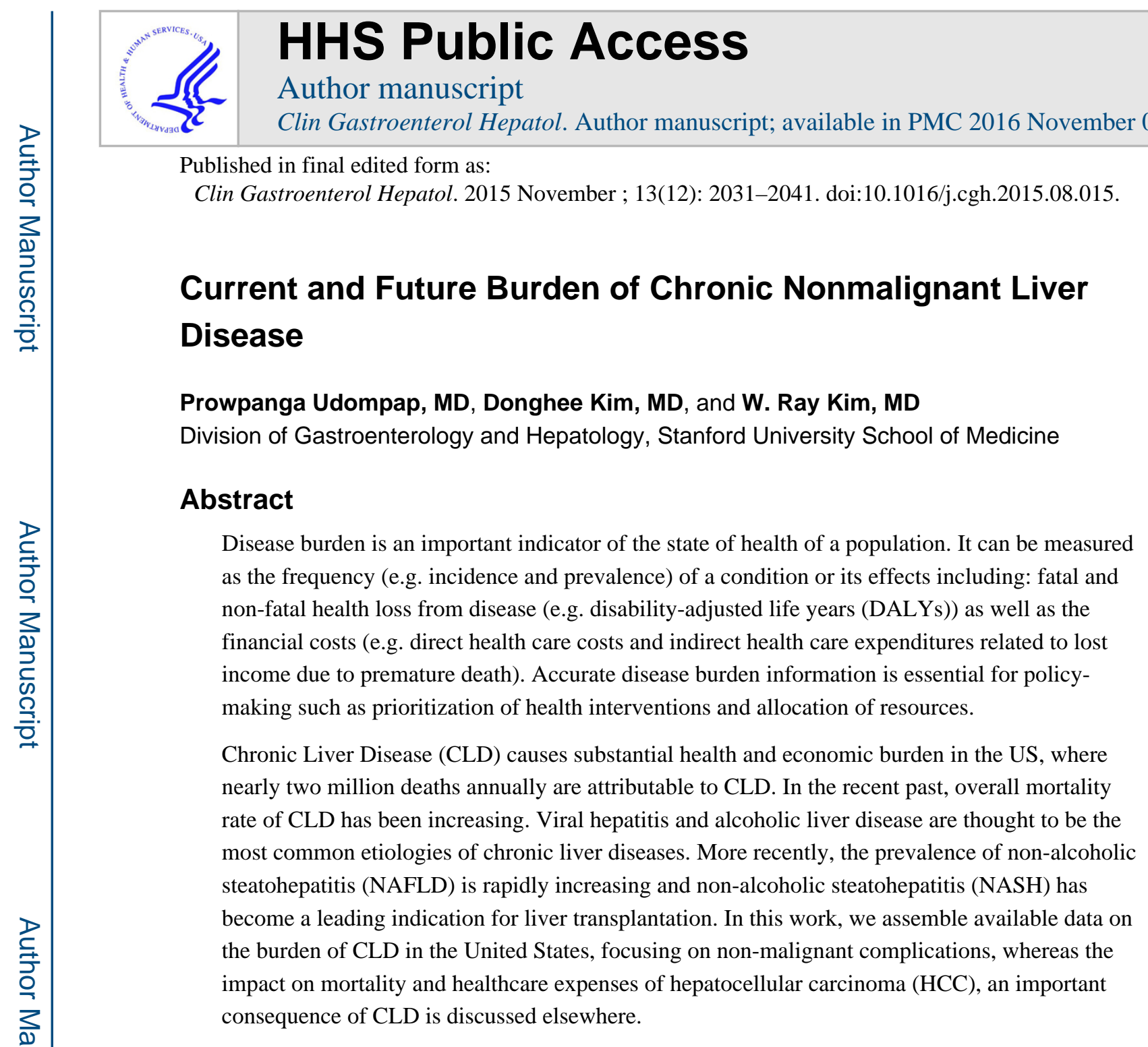

Globally, chronic liver disease (CLD) is an important source of health and economic burden. According to the Global Burden of Disease Study of 2010, 1.75 million deaths were attributable to CLD. There is a large degree of geographic variation in the burden of CLD, depending on the prevalence of causative factors such as viral hepatitis infection, including hepatitis B virus (HBV) and hepatitis C virus (HCV), alcohol consumption, diabetes and metabolic syndrome. In general, $\mathrm{HBV}$ infection tends to have a large burden in resourcelimited countries and nonalcoholic fatty liver disease (NAFLD) in more established economies, whereas HCV infection and alcohol use are prevalent throughout. Since CLD has a long latent period between initial occurrence of liver disease and diagnosis of CLD, it is difficult to determine the accurate incidence of CLD. Instead, most available epidemiological data estimate prevalence of CLD and its later consequences.

\footnotetext{
Address correspondence to: W. Ray Kim, MD, Professor and Chief, Division of Gastroenterology and Hepatology, Stanford University School of Medicine, 300 Pasteur Dr., Stanford, CA 94305, wrkim@ stanford.edu.

Conflicts of interest: All authors declare that there are no conflicts of interest.

Publisher's Disclaimer: This is a PDF file of an unedited manuscript that has been accepted for publication. As a service to our customers we are providing this early version of the manuscript. The manuscript will undergo copyediting, typesetting, and review of the resulting proof before it is published in its final citable form. Please note that during the production process errors may be discovered which could affect the content, and all legal disclaimers that apply to the journal pertain.
} 
With regard to CLD in the US, recent data indicate that there has been a substantial increase in the burden of CLD. Although, the exact prevalence of cirrhosis worldwide remains unknown ${ }^{1}$, the prevalence of cirrhosis in the US was estimated to be approximately $0.27 \%$, corresponding to 633,323 adults. ${ }^{2}$ The National Center for Health Statistics reports that CLD and cirrhosis represent the $12^{\text {th }}$ leading cause of death in the United States in 2013, accounting for 36,427 (1.4\%) of the 2,596,993 deaths (mortality rate, 11.5/100,000). This mortality rate increased over time, from 9.4 in 1999 to 11.5 in 2013 (www.cdc.gov/nchs/ data/nvsr/nvsr61/nvsr61_04.pdf). ${ }^{3}$

More impressively, the global burden of disease investigators calculated a metric that addresses premature mortality, namely years of life lost (YLL), cirrhosis was one of the conditions that had the most rapid increase in the burden between 1990 and 2010. In 1990, cirrhosis was ranked as the $14^{\text {th }}$ highest YLL in the US with an estimated 917,300 years of life lost. By 2010, cirrhosis rose to $8^{\text {th }}$ with $1,232,700$ years lost, which places cirrhosis between diabetes $\left(7^{\text {th }}\right)$ and Alzheimer's disease $\left(9^{\text {th }}\right)$, higher than colorectal cancer $\left(10^{\text {th }}\right)$, breast cancer $\left(13^{\text {th }}\right)$ or chronic kidney disease $\left(16^{\text {th }}\right)$. In terms of number of deaths, cirrhosis claimed 33,700 lives in 1990, which increased to 49,500 lives in $2010 .{ }^{4}$ Globally, cirrhosisrelated deaths increased approximately $46 \%$ from 838,000 lives in 1990 to 1,221,100 lives in $2013 .^{5}$

Figure 1 depicts mortality rates from liver disease (ICD-10: K70-76) in the US by gender and Hispanic ethnicity for years 1999-2013 from Deaths: Final Data for 2013 collected by Centers for Diseases Control and Prevention (CDC). ${ }^{6}$ In general, men have higher mortality from liver disease than in women, whereas Hispanic ethnicity did not affect mortality. Over time, there was an increase in mortality from liver disease. In women, mortality from liver disease rose from 11.8 deaths per 100,000 in 1999 to 15.2 per 100,000 in 2013. In men, it increased from 22.2 deaths per 100,000 to 26.7 per 100,000 during the same period. Figure 2 analyzes the same data by age groups. Overall, mortality from liver disease increased with age. The increase in mortality over time was most pronounced in people of 55-64 years in age, followed by those of 45-54 years. An increase is also seen in the 65-74 year old group in the last few years. These increasing trends in mortality are likely related to the aging of the HCV birth cohort (please see below). Finally, Figure 3 displays racial differences in liver disease mortality. Mortality is highest among Native Americans and Alaskan natives, followed by Caucasians, Africans, and Asian-Pacific Islanders. In all racial groups, men have higher mortality from liver disease than women. An increase in liver mortality over time was mainly seen among Caucasian Americans, both men and women, as well as among Native American or Alaskan native women. Again, at least part of this trend may be attributed to $\mathrm{HCV}$. While several reasons may be postulated to underlie the racial disparity in CLD mortality, these data could help guide appropriate resource allocation for prevention and treatment as well as to improve access to healthcare for the underprivileged. ${ }^{7}$

Epidemiological data other than mortality related to liver disease tend to be difficult to obtain on a population level in the US. Commonly, epidemiologic data have been derived from academic, tertiary referral practices, which likely may not represent the true epidemiological burden of CLD in the whole US population. ${ }^{8,9}$ An example may be trends in liver transplant waiting list (Figure 4). At the end of 2002, the year in which the current 
MELD score-based allocation system was implemented, there were 15,507 patients awaiting an organ, of whom 400 had a diagnosis of a liver malignancy and 15,107 did not. Ten years later, at the end of 2012, 15,290 patients were waiting, of whom 13,944 did not have a diagnosis of malignancy. The decrease in liver transplant waitlist registrants likely reflects changes in listing practices rather than a true reduction in the burden of end stage liver disease in the US. Over time, as organ scarcity worsened, fewer patients with low MELD score have been listed. ${ }^{10}$

Figures 5A and 5B show the breakdown of underlying liver disease diagnosis in patients awaiting and undergoing liver transplantation in 2012 respectively. The single most common etiology represented in liver transplant candidates is chronic HCV infection, which accounted for nearly $1 / 3$. The other major diagnoses included ALD and other/unknown etiologies - most of these latter patients are presumed to have NAFLD. A similar pattern is seen with patients undergoing liver transplantation with $\mathrm{HCV}$ and alcohol being the most common etiologies at the time of LT.

\section{Chronic Hepatitis C Virus infection}

An estimated 2-3\% of the world's population or 130-170 million people are living with chronic HCV infection. The epidemiology of HCV infection varies throughout the world, with its prevalence ranging from $<1 \%$ to $>10 \% .{ }^{11}$ Egypt is known to have the highest prevalence of $\mathrm{HCV}$ infection, which has been attributed to healthcare-related viral transmission. ${ }^{12}$ While there is no effective vaccine against $\mathrm{HCV}$, prevention of transmission and widespread application of effective antiviral agents may potentially reduce the burden of HCV infection over time. To date, however, lack of screening and limited access to appropriate diagnosis and treatment remain barriers to substantially reducing the global burden of $\mathrm{HCV}$ and morbidity and mortality from cirrhosis and liver cancer complicating chronic HCV infection continue to increase.

In the US, HCV infection is known as the most common chronic blood-borne infection. The National Health and Nutrition Examination Survey (NHANES) data have been used to estimate its prevalence. There have been three publications addressing the HCV prevalence in the NHANES samples. These reported the prevalence of HCV infection (i.e., detectable serum HCV RNA) at $1.3 \%$ for surveys from 1988-94, at 1.3\% for 1999-2002 and at $1.0 \%$ for 2003-2010, corresponding to 2.7 (95\% confidence interval [CI]: 2.4-3.0) million, 3.2 (95\%CI: 2.7-3.9) million and 2.7 (95\%CI: 2.2-3.2) million American adults with HCV viremia, respectively. It is likely that these data underestimate the true prevalence of $\mathrm{HCV}$, as NHANES does not include parts of the population that are expected to have high prevalence of $\mathrm{HCV}$ infection, including the homeless and the incarcerated.

Chronic HCV infection may result in cirrhosis, end-stage liver diseases (ESLD), and HCC. In a study that utilized 2007 death certificate data, HCV infection was listed as the underlying cause of 6,605 deaths and as the underlying or contributing cause of 15,106 deaths with the age-adjusted mortality rate of 4.58 deaths per 100,000 persons per year (95\%CI: 4.50-4.67). ${ }^{13}$ In comparison, HIV infection was listed as the underlying cause of 11,332 deaths and as the underlying or contributing cause of 12,734 deaths (age-adjusted 
mortality rate of 4.16 deaths per 100,000 persons per year (95\%CI: 4.09-4.24). Thus, as of 2007, HCV infection resulted in more deaths than HIV infection in the US. ${ }^{14}$

A peculiar aspect of $\mathrm{HCV}$ infection in the US is that the infection is concentrated in a certain age group, namely individuals born between 1945-1965, the so-called baby-boomer generation. This is thought to reflect high-risk behaviors (e.g., injection drug use while sharing needles) as well as transfusion of contaminated blood prior to the development of diagnostic tests for HCV. More recently, however, resurgence of acute HCV infection has been reported as a result of increased use of heroin among young adults. As HCV infection remains asymptomatic prior to development of complications of advanced liver disease, many of these individuals remain to be diagnosed. In an estimate based on the NHANES sample, nearly 50\% of American adults with HCV infection were unaware of their infection. Even among those who were diagnosed, only $38 \%$ accessed healthcare for further diagnosis and treatment.

Projection studies have estimated that while the incidence of new HCV infection in the US decreased over time, the number of individuals living with advanced fibrosis and cirrhosis will rise as the birth cohort of baby boomers with $\mathrm{HCV}$ infection grows older and their duration of infection reaches long enough time for their liver fibrosis to have progressed to cirrhosis. However, systematic data to assess the prevalence and burden of advanced liver disease as a result of chronic HCV infection have been sparse. Kanwal et al utilized data from the Veterans Administration data to assess time trends in the prevalence of cirrhosis and its related complications. Among veterans with $\mathrm{HCV}$ infection, the proportion diagnosed with cirrhosis increased from 9\% in 1996 to $18.5 \%$ in 2006 and that with decompensated cirrhosis from $5 \%$ in 1996 to $11 \%$ in $2006 .{ }^{15}$

These increases in morbidity and mortality associated HCV infection have a substantial impact on healthcare costs. Several studies have utilized health insurance payer databases to estimate all-cause and HCV-related healthcare costs. Gordon et al divided their 53,796 patients with HCV infection into noncirrhotic liver disease ( $\mathrm{NCD}, \mathrm{n}=41,858,78 \%)$, compensated cirrhosis (CC, $n=3,718,7 \%)$, and end stage liver disease $(n=8,220,15 \%)$. When the per-patient-per-month (PPPM) healthcare costs were calculated, the mean allcause PPPM costs were $32 \%$ and $247 \%$ higher for patients with CC and ESLD compared to those with NCD ( $\$ 1,870$ and $\$ 4,931$ versus $\$ 1,420 ; \mathrm{P}<0.001)$. The top three cost components included pharmacy, ambulatory care, and hospital inpatient, which altogether accounted for $90 \%$ of NCD costs and $93 \%$ of CC and ESLD costs. The largest cost components were inpatient costs for those with ESLD (56\%) and ambulatory costs for those with CC and NCD (37\% and 36\%, respectively). More than half (56\%) of the healthcare costs were attributable to $\mathrm{HCV}$ and this proportion increased with severity $(46 \%, 57 \%$, and $71 \%$ for patients with NCD, CC, and ESLD, respectively). El Khoury et al. studied the components of the costs involved in the management of patients with ESLD. They estimated the cost of a liver transplant at $\$ 201,110(\$ 178,760-\$ 223,460)$, variceal hemorrhage at $\$ 25,595$, refractory ascites at $\$ 24,755$, and hepatic encephalopathy at $\$ 16,430$, compared to the cost of compensated cirrhosis of $\$ 585-\$ 1,110 .{ }^{16}$ Putting available data together, Razavi et al estimated that the total healthcare costs associated with HCV infection may be as high as $\$ 6.5$ billion annually. ${ }^{14}$ 
While these data on the current burden of $\mathrm{HCV}$ infection is already substantial, projection studies have forecasted that the future burden will be even higher, because the prevalence of advanced liver disease is expected to continue to rise. Davis et al. projected that from the year 2000 to 2020, the prevalence of compensated cirrhosis and HCC will increase by over $80 \%$, decompensated cirrhosis by over $100 \%$ and liver-related deaths by $181 \% .{ }^{17}$ Razavi et al projected that the prevalence of compensated cirrhosis would peak in 2015 at 626,500 cases, while that of decompensated cirrhosis would reach 107,400 in 2019. ${ }^{14}$ As a result, the total healthcare costs for HCV would increase to a peak in 2024 at $\$ 9.1$ billion. The costs associated with compensated cirrhosis are expected to peak in 2022 at $\$ 1.9$ billion and those for decompensated cirrhosis in 2025 at $\$ 4.2$ billion. According to the study from Hatzakis et al., the prevalence of $\mathrm{HCV}$ viremia in most countries has already peaked. Yet, the prevalence of ESLD and liver-related deaths will continuously increase until 2030. ${ }^{18}$ Hopefully, widespread application of antiviral agents will dampen these future impacts.

HCV therapy has been revolutionized by the approval of the direct-acting antiviral agents (DAAs) and availability of new regimens for chronic $\mathrm{HCV}$ infection. These innovations afford shorter treatment durations, lower pill burden, fewer side effects, and higher rates of sustained virological response compared with the conventional therapies. With the implementation of birth-cohort screening and the availability of highly effective new therapies, Kabiri et al projected that $\mathrm{HCV}$ infection would become a rare disease in the US by $2036 .{ }^{19}$

At the same time, the new DAA regimens present challenges to public health as well. While DAAs are expected to reduce the number of patients with ESLD and liver transplantation, the high cost of DAAs places a substantial burden on the healthcare system. Economic constraints and limited access to healthcare may further exacerbate disparities that are already present among $\mathrm{HCV}$ patients. Moreover, potential consequences of emergence of resistance-associated variant viruses and the emerging concerns for cross-resistance need to be recognized. ${ }^{20}$ For HCV patients in resource-limited regions, barriers to HCV care not only includes high cost of antiviral therapies, but also the lack of medical infrastructure and laboratories, as well as shortage of healthcare workers and diagnostic tools. ${ }^{21,22}$

In summary, the prevalence of chronic $\mathrm{HCV}$ infection has the geographic variation ranging from $<1 \%$ to $>10 \%$ throughout the world. HCV infection is the most common indication for liver transplantation in the US. Though the incidence of HCV infection decreases, the mortality rate continuously increases and leads to substantial healthcare and economic burden. The promising outcomes of HCV treatment with the DAAs suggest that the novel, highly effective therapies may help reduce the long term burden. However, obstacles remain in the HCV treatment, especially in the resource-limited settings. These challenges call for collaboration among policy makers, pharmaceutical companies, health-care providers and researchers.

\section{Alcoholic Liver Disease (ALD)}

Ethanol, widely consumed in most parts of the world, is a well-known cause of chronic liver disease. ALD ranges from reversible alcoholic fatty liver, to alcoholic hepatitis, and to 
cirrhosis and ESLD. Alcohol, in addition, may accelerate the progression of coexisting liver diseases, for example HCV infection. ${ }^{23}$ Clearly, not all drinkers develop ALD - in addition to the duration and amount of drinking, other factors such as gender and genetic predisposition may determine the incidence and severity of ALD. ${ }^{24}$

ALD is an important global public health problem. In 2010, alcoholic cirrhosis was responsible for 493,300 deaths (death rate $=7.2$ deaths per 100,000) and for loss of $14,544,000$ disability adjusted life years (DALYs). ALD accounts for $47.9 \%$ of all cirrhosis deaths and $46.9 \%$ of all cirrhosis DALYs. Central Europe had the highest percentages of cirrhosis deaths and DALYs attributable to alcohol consumption, with $72.3 \%$ of all cirrhosis deaths and $74.6 \%$ of all cirrhosis DALYs. ${ }^{25}$ The World Health Organization has a goal to reduce ALD mortality to below 3.2 per 100,000 by year 2020 .

It is estimated that as of $2013,16.6$ million American (7\%) adults ( $\geq 18$ years) had an alcohol use disorder, consisting of 10.8 million men and 5.8 million women. ${ }^{26} \mathrm{Up}$ to 30 $45 \%$ of patients with chronic alcohol use disorder may develop alcoholic hepatitis sometime during their lifetime. ALD remains a major cause of cirrhosis and constitutes the second most common indication for liver transplantation in the US. Because only a fraction of patients with ALD qualify for liver transplantation candidacy, liver transplantation waiting list database is not a representative sample for epidemiological studies of ALD in the population. Further, since many ALD patients lack optimal access to healthcare, analyses based on healthcare administrative databases likely underestimate the true burden of ALD on the population level.

Paula et al conducted a longitudinal assessment of ALD mortality using death certificate data from the National Vital Statistics System for $1980-2003 .{ }^{27}$ A total of 287,365 records were identified as potential ALD deaths over the 24-year period. The age- and sex- adjusted incidence rate of ALD-related deaths was 6.9/100,000 persons in 1980 and 4.4/100,000 persons in 2003. During the study period, ALD mortality (per 100,000 persons) decreased from 6.3 to 4.5 among Caucasians, 11.6 to 4.1 among African Americans, and 8.0 to 3.7 among other race group. When the mortality rate trend for ALD was assessed in conjunction with that for $\mathrm{HCV}$, the reduction in ALD mortality was reciprocally matched by an increase in mortality from HCV, which reached 2.9/100,000 persons by 2003. These data suggest that there were $\mathrm{HCV}$ deaths misclassified as ALD deaths prior to recognition of $\mathrm{HCV}$ and that ALD mortality may not have decreased over time. Age-specific mortality related to ALD was highest in decedents of $45-64$ years in age. More recent data confirm that alcoholrelated mortality affects mainly on young and middle-age individuals and estimate that approximately 18,000 Americans died from ALD in 2013. ${ }^{28}$

The cost of excessive alcohol consumption in the US is estimated to have reached $\$ 223.5$ billion in 2006, predominantly resulting from workplace productivity losses ( $72 \%$ of the total cost), healthcare expenses ( $11 \%$ of total), criminal justice expenses related to excessive alcohol consumption ( $9 \%$ of total), and motor vehicle accident costs ( $6 \%$ of the total). ${ }^{29}$ These financial and human costs of alcohol use disorders including ALD are clearly enormous yet potentially preventable. Although some alcoholic hepatitis may be 
pharmaceutically treated, the most effective means to reduce the burden of ALD remains to prevent, recognize and intervene with the underlying alcohol use disorders. ${ }^{30}$

In summary, ALD ranges from reversible alcoholic fatty liver, to alcoholic hepatitis, and to cirrhosis and ESLD. It accounts for nearly half of all cirrhosis and remains a leading indication for liver transplantation in the US. While ALD only accounts for a fraction of alcohol use disorders, it incurs enormous financial and human costs. The most effective means to reduce the burden of ALD is to prevent, recognize and intervene with the underlying alcohol use disorders.

\section{Nonalcoholic Fatty Liver Diseases (NAFLD)}

NAFLD is defined as the presence of hepatic steatosis after the exclusion of other causes of hepatic fat accumulation, including significant alcohol consumption; other causes of liver disease; and other medical conditions. NAFLD includes a spectrum of histologic abnormalities ranging from nonalcoholic fatty liver (NAFL) to nonalcoholic steatohepatitis (NASH), cirrhosis and eventually hepatocellular carcinoma. Although NAFLD is seen in all ethnic groups, it has a lower prevalence in African-Americans compared with Hispanic and Caucasian Americans, even after adjustment for obesity and insulin resistance, which may be related to ethnic differences in lipid homeostasis. ${ }^{31,32}$ According to the Dallas Heart Study, a population-based cohort study performed in an ethnically diverse community in the US, the prevalence of NAFLD was approximately $34 \% .33$

Prevalence estimates for NAFLD has varied among studies in part because of differences in the sensitivity of the test modality used to determine steatosis of the liver. In the Framingham Heart Study, the prevalence of NAFLD was 17\%, when assessed by computed tomography. ${ }^{34}$ A study utilizing the NHANES data revealed that ultrasound-diagnosed steatosis was as common as $34 \% .{ }^{35} \mathrm{In}$ a study based on a largely middle-aged Americans, NAFLD and histologically confirmed NASH was found in $46 \%$ and $12.2 \%$, respectively. ${ }^{36}$ Finally, a recent meta-analysis estimated the prevalence of NAFLD and NASH to be 6-35\% (median 20\%) and 3-5\%, respectively. ${ }^{37}$

NAFLD is pathogenetically associated with obesity, hyperinsulinemia and insulin resistance and the increasing prevalence of obesity, type II diabetes, and metabolic syndrome in the general population has led a rapid rise in the prevalence of NAFLD. ${ }^{38-40}$ A study based on NHANES data estimated that the prevalence of NAFLD increased from 18\% in 1988-1991 to $29 \%$ in $1999-2000$ to $31 \%$ in $2011-2012 .^{41}$

Several cohort studies have reported the progression of NAFLD to cirrhosis. However, the rate of progression is variable - it is higher in patients with NASH compared to those with NAFL. Adams et al. reported incident cirrhosis in $3.1 \%$ of cases during 7.6 years of followup in Olmsted County. ${ }^{42}$ In this NAFLD cohort, cirrhosis did not develop in patients with NAFL. In subjects diagnosed with NASH, the progression rate to end stage liver disease was reportedly as high as $10 \%$ during 13.7 years of followup. ${ }^{43}$ Another study reported that histological fibrosis, rather than steatosis grade or presence of NASH, was associated with liver-related events. ${ }^{44,45}$ When hepatic fibrosis was evaluated by noninvasive NAFLD 
fibrosis score, liver-related events were more frequent in the intermediate (HR 7.7, 95\% CI 1.4-42.7) and high-risk groups (HR 34.2, 95\% CI 6.5-180.1) than in the low-risk group. ${ }^{44}$

Studies evaluating long-term survival have shown that NAFLD was associated with increased overall mortality, with standardized mortality ratios of $1.3-2.6 .{ }^{42,43,46-49}$ Some of these studies are confounded because in analyzing survival of NAFLD patients, they failed to account for obesity and related metabolic traits. Ekstedt et al. demonstrated that NAFLD patients have increased risk of death, attributable to cardiovascular disease and liver-related disease during a mean follow-up of 26.4 years. ${ }^{50}$ Patients with NAFL may be more likely to die from cardiovascular causes rather than advanced liver disease. ${ }^{51}$ Moreover, fibrosis stage predicted both overall and disease-specific mortality. ${ }^{44,50}$ Soderberg et al. studied liver biopsy-diagnosed NAFLD and showed that mortality was increased in the NASH group but not in those with simple NAFL. ${ }^{49}$ A population-based study using NHANES III evaluated the association between noninvasive fibrosis markers and mortality and demonstrated that patients with advanced fibrosis had an increased risk of overall mortality compared with patients without advanced fibrosis. The increase in mortality was almost entirely from cardiovascular causes. ${ }^{35}$ Other investigators have shown that NASH-related cirrhosis is associated with mortality comparable to HCV-related cirrhosis. ${ }^{52-54}$ NAFLD is thought to contribute to fibrosis, mortality and disease burden when it coexists with other CLD. In summary, most studies have consistently shown that NASH with advanced fibrosis is associated with increased mortality whereas NAFL without fibrosis has a benign long-term outcome.

NASH is quickly becoming a major etiology in liver transplantation in the US and it may soon become the most common indication. ${ }^{55,56}$ According to data from the Scientific Registry of Transplant Recipients (SRTR), the proportion of recipients receiving a liver transplant for NASH increased from $1.2 \%$ in 2001 to $9.7 \%$ in $2009 .{ }^{55}$ Between 2004 and 2013, new waitlist registrants with NASH increased by $170 \%$, compared to $45 \%$ for ALD and $14 \%$ for $\mathrm{HCV} .57$

While it is likely that NAFLD has a substantial economic impact, representative data are scarce. A German population cohort study reported that subjects with ultrasonographic fatty liver disease with increased liver enzyme had $26 \%$ higher overall healthcare costs over 5 years of follow-up, controlling for comorbid conditions. ${ }^{58}$ According to data from national outpatient claims of Medicare beneficiaries (2005 to 2010), the number of outpatient visits because of NAFLD rose between 2005 and 2010 - the mean annual charge and payment increased significantly from $\$ 2,624$ and $\$ 561$ in 2005 to $\$ 3,608$ and $\$ 629$ ( $p<0.05$ ), respectively. ${ }^{59}$

In summary, the increasing prevalence of obesity and type II diabetes and the metabolic syndrome is leading to an increased prevalence of NAFLD in the US. It has become a leading cause of liver transplantation in the US. The mortality and financial burden related to NAFLD is not limited to liver related events but includes the increased risk in cardiovascular morbidity and mortality. 


\section{Chronic Hepatitis B Virus infection}

Globally, HBV remains an important cause of acute and CLD. At least 240 million individuals have chronic HBV infection - HBV may account for up to $30 \%$ of cirrhosis and $45 \%$ of HCC. The prevalence of HBV infection varies by geography, with the highest (>8\%) prevalence in sub-Saharan Africa and Asia. In contrast, HBV prevalence is lowest $(<2 \%)$ in regions such as North America, Western Europe and Australia ${ }^{60}$ With increasing uptake of universal infant immunization, the global prevalence of HBV infection is expected to decrease.

In the US, 700,000 to 1.4 million are estimated to have chronic HBV infection. Chronic HBV infection is most commonly a result of transmission in infancy or childhood which occurs in HBV endemic populations, whereas most incident HBV infections in the US are in adults and rarely become chronic. ${ }^{61}$ Thus, the bulk of chronic HBV infection in the US is borne by immigrants or their children who have come from HBV-endemic areas of the world. Kowdley et al. estimated that $3.5 \%$ or $1.23-1.42$ million of all foreign-born persons in the US have chronic hepatitis B, which is more than 10-fold higher than the prevalence of HBV in the general US population. ${ }^{62}$ In the recent few decades, more than $60 \%$ of new immigrants to the US come from countries of high HBV endemicity. ${ }^{63}$ However, there are few empirical data to accurately measure the prevalence of HBV infection. For example, data based on NHANES samples indicate that the age-adjusted prevalence of HBsAg seropositivity decreased from $0.38 \%$ in $1988-1994$ to $0.27 \%$ in $1999-2006$. These are, however, likely underestimates, as NHANES samples do not include sufficient number of individuals from population subgroups with high HBV prevalence.

In the analysis of 2007 mortality data by Ly et al ${ }^{13}$, HBV infection was listed as the underlying cause of death in 724 decedents and as the underlying or contributing cause of death in 1,815 . The age-adjusted mortality rate was 0.56 death per 100,000 persons per year ( $95 \% \mathrm{CI}, 0.54$ to 0.59 ), which is approximately $1 / 8$ of that for $\mathrm{HCV}$. The lower death rate for $\mathrm{HBV}$ is not only attributable to the lower prevalence of HBV than HCV in the general population, but also consequent to widespread institution of effective antiviral therapy. In an analysis of liver transplant waiting list, the incidence of waitlist registration for ESLD from HBV cirrhosis decreased significantly coincident with the introduction of effective oral antiviral agents, whereas the effect of those agents on the need for liver transplantation for HCC was less certain.

Today, oral antivirals are the mainstay of chronic HBV therapy. The cost depends on the regimens and the duration of treatment. Entecavir (ETV) and tenofovir disoproxil fumarate (TDF) are potent nucleoside and nucleotide analogues, respectively, recommended as firstline agents for chronic hepatitis B. The approximate annual cost of for ETV and TDF has been reported to be $\$ 5100-5,800$ and $\$ 3,400-3,900$ respectively. ${ }^{64,65}$

There are limited data about the impact of HBV on healthcare resource utilization. According to a report on the burden of digestive diseases, outpatient visits for a HBV-related diagnosis occurred at a rate of $<100$ visits per 100,000 in 1996, which increased to $>400$ visits per 100,000 by 2004 . Similarly, the rate of hospitalization for a HBV-related illness 
was 5 per 100,000 in 1996, which increased to $>20$ per 100,000 in 2002. The total charges for HBV hospitalizations increased from $\$ 357$ million in 1990 to $\$ 1.5$ billion in 2003. As of 2006, hospitalization charges did not increase further, which may also reflect the impact of antiviral therapy. 9

In summary, while HBV does not have as large a burden as HCV does in the US as a whole, it affects certain groups of Americans, namely recent immigrants from endemic countries. Recent data suggest that effective antiviral therapy has contributed to a substantial decrease in morbidity and healthcare services related to ESLD (e.g., liver transplantation). However, continued emphasis on screening, early diagnosis and treatment is needed to continue the trend.

\section{Metabolic Liver Diseases}

Hereditary Hemochromatosis $(\mathrm{HH})$ is known as the most common genetic disease in North America, although it still represents a relatively uncommon etiology of CLD. HH is most commonly characterized by defects in the HFE gene, although more recently, mutations in other genes coding for iron regulatory proteins have been discovered to be responsible for the inherited iron overload syndrome (i.e.hepcidin (HAMP), hemojuvelin (HJV), transferrin receptor 2 (TfR2) and ferroportin (SLC40A1)). The HFE gene codes for a membrane protein involved in dietary iron absorption. ${ }^{66} \mathrm{Up}$ to $90 \%$ of typical $\mathrm{HH}$ patients carry a $\mathrm{C} 282 \mathrm{Y}$ mutation of the gene. Conversely, however, the penetrance of disease among subjects with the mutation is relatively low, suggesting contribution of non-genetic factors in the disease progression. ${ }^{67}$ The highest allelic prevalence of HFE gene mutation is seen in people of Northern European ancestry $(6 \%) .{ }^{68}$ The prevalence was only $0.11,0.027,0.014,0.012$ and $0.000039 \%$ in Native American, Hispanic, African American, Pacific Islander and Asian populations, respectively. 69

$\mathrm{HH}$ is an uncommon indication for liver transplantation, in part due to the higher morbidity and mortality from cardiac, infectious and malignant complications in liver transplantation for HH-related conditions. A single center UK study by Faisal et al. reported that $\mathrm{HH}$ accounted for $1 \%$ of the liver transplants performed over a period of 12 years. They revealed that postoperative infectious and cardiac complications are common. ${ }^{70}$

Wilson Disease (WD) is an autosomal recessive disorder of copper metabolism. The most common genetic abnormality associated with WD is absence of decrease in function of ATP7B protein, which leads to decreased copper excretion into bile, resulting in copper accumulation and injury. To date, more than 500 distinct mutations have been described, 380 of which have a confirmed role in the pathogenesis of the disease..$^{71}$ The average prevalence of WD worldwide is about 3 per 100,000. Liver involvement in WD is more common among children and younger adults, while neurological symptoms may be seen more often in older patients. ${ }^{72}$ Untreated patients may present with acute liver failure, which is associated with nearly $95 \%$ mortality unless liver transplantation is performed. ${ }^{73}$

WD is the primary indication for liver transplantation in $0.5 \%$ and $1.5 \%$ of adults and children respectively. ${ }^{74}$ In children, metabolic liver diseases are the second most common indication for liver transplantation after biliary atresia. Fifteen percent of children enrolled in 
the studies in the pediatric liver transplantation (SPLIT) registry underwent liver transplantation for metabolic diseases and $7.6 \%$ of them represented WD. ${ }^{75}$

Alpha-1 antitrypsin deficiency (AIATD) is known as a common genetic liver disease in infant and children. It is an autosomal co-dominant genetic disease affecting 1 per 3,0005,000 individuals ${ }^{76-78}$ and has been described in all races. However, it is most common in Whites $(14.0$ per 1,000$)$, as the most prevalent deficiency alleles, $\mathrm{Z}$ and $\mathrm{S}$ are strongly associated with Northern European ancestry (Z and S alleles), and some Southern European ancestry (S allele). It is less common in Hispanics $(9.1$ per 1,000) and African American (2.6 per 1,000) and extremely rare in Asian and Mexican Americans. ${ }^{79}$ It is estimated that 25 million people carry at least one defective A1AT gene. ${ }^{79}$ While 2-3\% of A1ATD children progress to advanced fibrosis and cirrhosis requiring liver transplantation, about one-third of genetically susceptible adults with the most severe phenotype (i.e., PiZZ) develop clinically significant liver injury. ${ }^{80}$ The association between heterozygosity of alpha 1-antitrypsin deficiency alleles and risk of developing CLD is controversial. ${ }^{81}$

According to Kemmer et al. study, A1ATD was the indication for liver transplantation in $1.1 \%$ of adults and $3.5 \%$ in children. The transplantation rate remained stable in adults, but the pediatric age groups had a downward trend, although the reason for the decline in the latter group remained unclear. ${ }^{82,83}$

In summary, three genetic diseases that commonly affect the liver are hereditary hemochromatosis (HH), Wilson disease (WD), and alpha-1 antitrypsin deficiency (A1ATD). National statistics for their morbidity, mortality or economic burden are sparse, since these diseases tend to be rare. Based on data in liver transplantation, HH, WD and A1ATD each may account for approximately $1 \%$ of liver transplantation.

\section{Autoimmune and Cholestatic Liver Diseases}

The natural history of autoimmune and cholestatic liver diseases is a chronically progressive course. Since these diseases are relatively rare and dependent on special laboratory or histological diagnosis, it is difficult to obtain population-based epidemiological data. ${ }^{8}$ This is particularly true with autoimmune hepatitis $(A I H)$ for which high quality population-based epidemiological data are unavailable. The incidence and prevalence of AIH was estimated to be $0.1-0.4$ per 100,000 children per year and 2.3-3.0 per 100,000 children, respectively. ${ }^{84}$ Adult estimates vary, with the incidence and prevalence ranging from 1.7 to 1.9 per 100,000 per year and from 16.9 to 42.9 per 100,000 , respectively. ${ }^{85-87}$

Primary Biliary Cirrhosis (PBC) is the most common form of autoimmune liver disease, although there is significant geographic variability. In a Canadian population-based study by Myers et al. the incidence and prevalence of PBC was 3.6 and 22.7 per 100,000, respectively. ${ }^{88}$ A US study in Olmsted County reported incidence of 2.7 per 100,000 and prevalence of 40.2 per $100,000 .{ }^{89}$ In contrast, the prevalence is much lower in other parts of the world, with 2.7 per 100,000 in $\mathrm{Japan}^{90}$ and 1.9 per 100,000 in Australia. ${ }^{91}$ Over past two decades, the number of $\mathrm{PBC}$ patients undergoing liver transplantation decreases. ${ }^{92}$ This may be partially explained by early diagnosis and treatment with ursodeoxycholic acid. ${ }^{93}$ 
Primary sclerosing cholangitis (PSC) is less common than PBC. A meta-analysis by Molodecky et al. estimated the overall incidence of PSC to be approximately 1 per $100,000^{94}$ and the prevalence according to the study by Toy et al was 4.15 per $100,000 .^{95}$ Recently, the incidence of PSC appears to be increasing, which may be a result of an increase in inflammatory bowel disease incidence worldwide. However, effective medical therapy to stop the disease progression remains to be discovered. ${ }^{96}$

In summary, autoimmune hepatitis (AIH), primary biliary cirrhosis (PBC), and primary sclerosing cholangitis (PSC) are relatively rare, which altogether account for a quarter of the indications for liver transplantation. To date, the comprehensive data related to the economic burden of autoimmune and cholestatic liver diseases are lacking. Furthermore, indirect costs from the pronounced symptoms of these diseases such as fatigue, pruritus may be substantial, but remains difficult to quantify.

\section{Conclusion}

The overall burden, including mortality, associated with CLD has increased in the US. Based on available epidemiological data, viral hepatitis, ALD, and NAFLD are the most common etiology for CLD. Over the foreseeable future, the burden of viral hepatitis is expected to decrease and that for NAFLD to increase, where no significant change in ALD is anticipated. While population level epidemiological trends have a large impact on these predictions, ground-breaking therapeutic innovations may also hasten or reverse these trends. Available data, or lack thereof, suggest that population-based data addressing CLD with a possible exception of viral hepatitis, are limited in the US and judicious societal investment in data infrastructure to detect and monitor the impact of CLD longitudinally is called for to guide public health policy and health care resources allocation decisions.

\section{References}

1. Schuppan D, Afdhal NH. Liver cirrhosis. Lancet. 2008; 371(9615):838-51. [PubMed: 18328931]

2. Scaglione S, Kliethermes S, Cao G, et al. The Epidemiology of Cirrhosis in the United States: A Population-based Study. J Clin Gastroenterol. 2014

3. Murphy, SL.; XJ; Kochanek, KD. Deaths: final data for 2010. Updated May 8, 2013. Centers for Disease Control and Prevention website;

4. Murray CJ, Atkinson C, Bhalla K, et al. The state of US health, 1990-2010: burden of diseases, injuries, and risk factors. JAMA. 2013; 310(6):591-608. [PubMed: 23842577]

5. Mortality GBD. Causes of Death C. Global, regional, and national age-sex specific all-cause and cause-specific mortality for 240 causes of death, 1990-2013: a systematic analysis for the Global Burden of Disease Study 2013. Lancet. 2015; 385(9963):117-71. [PubMed: 25530442]

6. Centers for Disease Control and Prevention. [Accessed June,2015] Deaths: Final Data for 2013. Available at http://www.cdc.gov/nchs/data/nvsr/nvsr64/nvsr64_02.pdf

7. Suryaprasad A, Byrd KK, Redd JT, et al. Mortality caused by chronic liver disease among American Indians and Alaska Natives in the United States, 1999-2009. Am J Public Health. 2014; 104(Suppl 3):S350-8. [PubMed: 24754616]

8. Kim WR, Brown RS Jr, Terrault NA, et al. Burden of liver disease in the United States: summary of a workshop. Hepatology. 2002; 36(1):227-42. [PubMed: 12085369]

9. Kim WR. Epidemiology of hepatitis B in the United States. Hepatology. 2009; 49(5 Suppl):S28-34. [PubMed: 19399791] 
10. Kim WR, Smith JM, Skeans MA, et al. OPTN/SRTR 2012 Annual Data Report: liver. American journal of transplantation : official journal of the American Society of Transplantation and the American Society of Transplant Surgeons. 2014; 14(Suppl 1):69-96.

11. Averhoff FM, Glass N, Holtzman D. Global burden of hepatitis C: considerations for healthcare providers in the United States. Clin Infect Dis. 2012; 55(Suppl 1):S10-5. [PubMed: 22715208]

12. Miller FD, Abu-Raddad LJ. Evidence of intense ongoing endemic transmission of hepatitis $C$ virus in Egypt. Proc Natl Acad Sci U S A. 2010; 107(33):14757-62. [PubMed: 20696911]

13. Ly KN, Xing J, Klevens RM, et al. The increasing burden of mortality from viral hepatitis in the United States between 1999 and 2007. Annals of internal medicine. 2012; 156(4):271-8. [PubMed: 22351712]

14. Razavi H, Elkhoury AC, Elbasha E, et al. Chronic hepatitis C virus (HCV) disease burden and cost in the United States. Hepatology. 2013; 57(6):2164-70. [PubMed: 23280550]

15. Kanwal F, Hoang T, Kramer JR, et al. Increasing prevalence of HCC and cirrhosis in patients with chronic hepatitis C virus infection. Gastroenterology. 2011; 140(4):1182-8. e1. [PubMed: 21184757]

16. El Khoury AC, Klimack WK, Wallace C, et al. Economic burden of hepatitis C-associated diseases in the United States. J Viral Hepat. 2012; 19(3):153-60. [PubMed: 22329369]

17. Davis GL, Albright JE, Cook SF, et al. Projecting future complications of chronic hepatitis $C$ in the United States. Liver Transpl. 2003; 9(4):331-8. [PubMed: 12682882]

18. Hatzakis A, Chulanov V, Gadano AC, et al. The present and future disease burden of hepatitis C virus (HCV) infections with today's treatment paradigm - volume 2. J Viral Hepat. 2015; 22(Suppl 1):26-45. [PubMed: 25560840]

19. Kabiri M, Jazwinski AB, Roberts MS, et al. The changing burden of hepatitis $\mathrm{C}$ virus infection in the United States: model-based predictions. Annals of internal medicine. 2014; 161(3):170-80. [PubMed: 25089861]

20. Soriano V, Labarga P, Fernandez-Montero JV, et al. The changing face of hepatitis $\mathrm{C}$ in the new era of direct-acting antivirals. Antiviral Res. 2013; 97(1):36-40. [PubMed: 23147192]

21. Thursz M, Fontanet A. HCV transmission in industrialized countries and resource-constrained areas. Nat Rev Gastroenterol Hepatol. 2014; 11(1):28-35. [PubMed: 24080775]

22. Lemoine M, Nayagam S, Thursz M. Viral hepatitis in resource-limited countries and access to antiviral therapies: current and future challenges. Future Virol. 2013; 8(4):371-80. [PubMed: 23662157]

23. Singal AK, Kuo YF, Anand BS. Hepatitis C virus infection in alcoholic hepatitis: prevalence patterns and impact on in-hospital mortality. Eur J Gastroenterol Hepatol. 2012; 24(10):1178-84. [PubMed: 22735607]

24. Singal AK, Jampana SC. Current management of alcoholic liver disease. Curr Drug Abuse Rev. 2014; 7(1):18-28. [PubMed: 25323125]

25. World Health Organization. Global Status Report on Alcohol and Health. Geneva, Switzerland: 2011. Available at: http://www.who.int/substance_abuse/publications/global_alcohol_report/ msbgsruprofiles.pdf [Accessed June 18, 2015]

26. Substance Abuse and Mental Health Services Administration. [Accessed June 18, 2015.] 2013 National Survey on Drug Use and Health (NSDUH). Table 2.46B-Alcohol Use, Binge Alcohol Use, and Heavy Alcohol Use in the Past Month among Persons Aged 18 or Older, by Demographic Characteristics: Percentages, 2012 and 2013. 2013. 2013. Availble at: http:// www.samhsa.gov/data/sites/default/files/NSDUHresultsPDFWHTML2013/Web/ NSDUHresults2013.pdf

27. Paula H, Asrani SK, Boetticher NC, et al. Alcoholic liver disease-related mortality in the United States: 1980-2003. Am J Gastroenterol. 2010; 105(8):1782-7. [PubMed: 20179691]

28. SAKA BS. Recent Trends in the Epidemiology of Alcoholic Liver Disease. Clinical Liver Disease. 2013; 2(2):53-6.

29. Ahmed S, Ali R, Qadir M, et al. Asthma in children: management issues for family doctors. Oman medical journal. 2010; 25(4):253-5. [PubMed: 22043352]

30. Rehm J, Samokhvalov AV, Shield KD. Global burden of alcoholic liver diseases. J Hepatol. 2013; 59(1):160-8. [PubMed: 23511777] 
31. Browning JD, Szczepaniak LS, Dobbins R, et al. Prevalence of hepatic steatosis in an urban population in the United States: impact of ethnicity. Hepatology. 2004; 40(6):1387-95. [PubMed: 15565570]

32. Ruhl CE, Everhart JE. Determinants of the association of overweight with elevated serum alanine aminotransferase activity in the United States. Gastroenterology. 2003; 124(1):71-9. [PubMed: 12512031]

33. Szczepaniak LS, Nurenberg P, Leonard D, et al. Magnetic resonance spectroscopy to measure hepatic triglyceride content: prevalence of hepatic steatosis in the general population. Am $\mathrm{J}$ Physiol Endocrinol Metab. 2005; 288(2):E462-8. [PubMed: 15339742]

34. Speliotes EK, Massaro JM, Hoffmann U, et al. Fatty liver is associated with dyslipidemia and dysglycemia independent of visceral fat: the Framingham Heart Study. Hepatology. 2010; 51(6): 1979-87. [PubMed: 20336705]

35. Kim D, Kim WR, Kim HJ, et al. Association between noninvasive fibrosis markers and mortality among adults with nonalcoholic fatty liver disease in the United States. Hepatology. 2013; 57(4): 1357-65. [PubMed: 23175136]

36. Williams CD, Stengel J, Asike MI, et al. Prevalence of nonalcoholic fatty liver disease and nonalcoholic steatohepatitis among a largely middle-aged population utilizing ultrasound and liver biopsy: a prospective study. Gastroenterology. 2011; 140(1):124-31. [PubMed: 20858492]

37. Vernon G, Baranova A, Younossi ZM. Systematic review: the epidemiology and natural history of non-alcoholic fatty liver disease and non-alcoholic steatohepatitis in adults. Aliment Pharmacol Ther. 2011; 34(3):274-85. [PubMed: 21623852]

38. Khashab MA, Liangpunsakul S, Chalasani N. Nonalcoholic fatty liver disease as a component of the metabolic syndrome. Current gastroenterology reports. 2008; 10(1):73-80. [PubMed: 18417046]

39. Ahmed MH, Abu EO, Byrne CD. Non-Alcoholic Fatty Liver Disease (NAFLD): new challenge for general practitioners and important burden for health authorities? Prim Care Diabetes. 2010; 4(3): 129-37. [PubMed: 20299294]

40. Dowman JK, Tomlinson JW, Newsome PN. Pathogenesis of non-alcoholic fatty liver disease. QJM. 2010; 103(2):71-83. [PubMed: 19914930]

41. Ruhl CE, Everhart JE. Fatty liver indices in the multiethnic United States National Health and Nutrition Examination Survey. Aliment Pharmacol Ther. 2015; 41(1):65-76. [PubMed: 25376360]

42. Adams LA, Lymp JF, St Sauver J, et al. The natural history of nonalcoholic fatty liver disease: a population-based cohort study. Gastroenterology. 2005; 129(1):113-21. [PubMed: 16012941]

43. Ekstedt M, Franzen LE, Mathiesen UL, et al. Long-term follow-up of patients with NAFLD and elevated liver enzymes. Hepatology. 2006; 44(4):865-73. [PubMed: 17006923]

44. Angulo P, Bugianesi E, Bjornsson ES, et al. Simple noninvasive systems predict long-term outcomes of patients with nonalcoholic fatty liver disease. Gastroenterology. 2013; 145(4):782-9. e4. [PubMed: 23860502]

45. Matteoni CA, Younossi ZM, Gramlich T, et al. Nonalcoholic fatty liver disease: a spectrum of clinical and pathological severity. Gastroenterology. 1999; 116(6):1413-9. [PubMed: 10348825]

46. Calori G, Lattuada G, Ragogna F, et al. Fatty liver index and mortality: the Cremona study in the 15th year of follow-up. Hepatology. 2011; 54(1):145-52. [PubMed: 21488080]

47. Jepsen P, Vilstrup H, Mellemkjaer L, et al. Prognosis of patients with a diagnosis of fatty liver--a registry-based cohort study. Hepato-gastroenterology. 2003; 50(54):2101-4. [PubMed: 14696473]

48. Ong JP, Pitts A, Younossi ZM. Increased overall mortality and liver-related mortality in nonalcoholic fatty liver disease. J Hepatol. 2008; 49(4):608-12. [PubMed: 18682312]

49. Soderberg C, Stal P, Askling J, et al. Decreased survival of subjects with elevated liver function tests during a 28-year follow-up. Hepatology. 2010; 51(2):595-602. [PubMed: 20014114]

50. Ekstedt M, Hagstrom H, Nasr P, et al. Fibrosis stage is the strongest predictor for disease-specific mortality in NAFLD after up to 33 years of follow-up. Hepatology. 2015; 61(5):1547-54. [PubMed: 25125077]

51. Teli MR, James OF, Burt AD, et al. The natural history of nonalcoholic fatty liver: a follow-up study. Hepatology. 1995; 22(6):1714-9. [PubMed: 7489979] 
52. Bhala N, Angulo P, van der Poorten D, et al. The natural history of nonalcoholic fatty liver disease with advanced fibrosis or cirrhosis: an international collaborative study. Hepatology. 2011; 54(4): 1208-16. [PubMed: 21688282]

53. Hui JM, Kench JG, Chitturi S, et al. Long-term outcomes of cirrhosis in nonalcoholic steatohepatitis compared with hepatitis C. Hepatology. 2003; 38(2):420-7. [PubMed: 12883486]

54. Sanyal AJ, Banas C, Sargeant C, et al. Similarities and differences in outcomes of cirrhosis due to nonalcoholic steatohepatitis and hepatitis C. Hepatology. 2006; 43(4):682-9. [PubMed: 16502396]

55. Charlton MR, Burns JM, Pedersen RA, et al. Frequency and outcomes of liver transplantation for nonalcoholic steatohepatitis in the United States. Gastroenterology. 2011; 141(4):1249-53. [PubMed: 21726509]

56. Wong RJ, Cheung R, Ahmed A. Nonalcoholic steatohepatitis is the most rapidly growing indication for liver transplantation in patients with hepatocellular carcinoma in the U.S. Hepatology. 2014; 59(6):2188-95. [PubMed: 24375711]

57. Wong RJ, Aguilar M, Cheung R, et al. Nonalcoholic steatohepatitis is the second leading etiology of liver disease among adults awaiting liver transplantation in the United States. Gastroenterology. 2015; 148(3):547-55. [PubMed: 25461851]

58. Baumeister SE, Volzke H, Marschall P, et al. Impact of fatty liver disease on health care utilization and costs in a general population: a 5-year observation. Gastroenterology. 2008; 134(1):85-94. [PubMed: 18005961]

59. Younossi ZM, Zheng L, Stepanova M, et al. Trends in outpatient resource utilizations and outcomes for Medicare beneficiaries with nonalcoholic fatty liver disease. J Clin Gastroenterol. 2015; 49(3):222-7. [PubMed: 24637730]

60. Ott JJ, Stevens GA, Groeger J, et al. Global epidemiology of hepatitis B virus infection: new estimates of age-specific HBsAg seroprevalence and endemicity. Vaccine. 2012; 30(12):2212-9. [PubMed: 22273662]

61. Seeff LB, Beebe GW, Hoofnagle JH, et al. A serologic follow-up of the 1942 epidemic of postvaccination hepatitis in the United States Army. N Engl J Med. 1987; 316(16):965-70. [PubMed: 2436048]

62. Kowdley KV, Wang CC, Welch S, et al. Prevalence of chronic hepatitis B among foreign-born persons living in the United States by country of origin. Hepatology. 2012; 56(2):422-33. [PubMed: 22105832]

63. Mitchell T, Armstrong GL, Hu DJ, et al. The increasing burden of imported chronic hepatitis B-United States, 1974-2008. PLoS One. 2011; 6(12):e27717. [PubMed: 22163270]

64. Buti M, Oyaguez I, Lozano V, et al. Cost effectiveness of first-line oral antiviral therapies for chronic hepatitis B : a systematic review. PharmacoEconomics. 2013; 31(1):63-75. [PubMed: 23329593]

65. Buti M, Brosa M, Casado MA, et al. Modeling the cost-effectiveness of different oral antiviral therapies in patients with chronic hepatitis B. J Hepatol. 2009; 51(4):640-6. [PubMed: 19576651]

66. Bacon BR, Adams PC, Kowdley KV, et al. Diagnosis and management of hemochromatosis: 2011 practice guideline by the American Association for the Study of Liver Diseases. Hepatology. 2011; 54(1):328-43. [PubMed: 21452290]

67. Powell LW, Dixon JL, Ramm GA, et al. Screening for hemochromatosis in asymptomatic subjects with or without a family history. Arch Intern Med. 2006; 166(3):294-301. [PubMed: 16476869]

68. Distante S, Robson KJ, Graham-Campbell J, et al. The origin and spread of the HFE-C282Y haemochromatosis mutation. Hum Genet. 2004; 115(4):269-79. [PubMed: 15290237]

69. Allen KJ, Gurrin LC, Constantine CC, et al. Iron-overload-related disease in HFE hereditary hemochromatosis. N Engl J Med. 2008; 358(3):221-30. [PubMed: 18199861]

70. Dar FS, Faraj W, Zaman MB, et al. Outcome of liver transplantation in hereditary hemochromatosis. Transpl Int. 2009; 22(7):717-24. [PubMed: 19490544]

71. European Association for Study of L. EASL Clinical Practice Guidelines: Wilson's disease. J Hepatol. 2012; 56(3):671-85. [PubMed: 22340672]

72. Roberts EA, Schilsky ML. American Association for Study of Liver D. Diagnosis and treatment of Wilson disease: an update. Hepatology. 2008; 47(6):2089-111. [PubMed: 18506894] 
73. Bellary S, Hassanein T, Van Thiel DH. Liver transplantation for Wilson's disease. J Hepatol. 1995; 23(4):373-81. [PubMed: 8655953]

74. Arnon R, Annunziato R, Schilsky M, et al. Liver transplantation for children with Wilson disease: comparison of outcomes between children and adults. Clin Transplant. 2011; 25(1):E52-E60. [PubMed: 20946468]

75. Arnon R, Kerkar N, Davis MK, et al. Liver transplantation in children with metabolic diseases: the studies of pediatric liver transplantation experience. Pediatr Transplant. 2010; 14(6):796-805. [PubMed: 20557477]

76. Colp C, Pappas J, Moran D, et al. Variants of alpha 1-antitrypsin in Puerto Rican children with asthma. Chest. 1993; 103(3):812-5. [PubMed: 8449073]

77. Silverman EK, Miletich JP, Pierce JA, et al. Alpha-1-antitrypsin deficiency. High prevalence in the St. Louis area determined by direct population screening. Am Rev Respir Dis. 1989; 140(4):9616. [PubMed: 2679271]

78. O'Brien ML, Buist NR, Murphey WH. Neonatal screening for alpha1-antitrypsin deficiency. J Pediatr. 1978; 92(6):1006-10. [PubMed: 307054]

79. de Serres FJ, Blanco I, Fernandez-Bustillo E. Genetic epidemiology of alpha-1 antitrypsin deficiency in North America and Australia/New Zealand: Australia, Canada, New Zealand and the United States of America. Clin Genet. 2003; 64(5):382-97. [PubMed: 14616761]

80. Sveger T. The natural history of liver disease in alpha 1-antitrypsin deficient children. Acta Paediatr Scand. 1988; 77(6):847-51. [PubMed: 2905108]

81. Fairbanks KD, Tavill AS. Liver disease in alpha 1-antitrypsin deficiency: a review. Am J Gastroenterol. 2008; 103(8):2136-41. quiz 42. [PubMed: 18796107]

82. Carey EJ, Iyer VN, Nelson DR, et al. Outcomes for recipients of liver transplantation for alpha-1antitrypsin deficiency-related cirrhosis. Liver Transpl. 2013; 19(12):1370-6. [PubMed: 24019185]

83. Kemmer N, Kaiser T, Zacharias V, et al. Alpha-1-antitrypsin deficiency: outcomes after liver transplantation. Transplant Proc. 2008; 40(5):1492-4. [PubMed: 18589136]

84. Deneau M, Jensen MK, Holmen J, et al. Primary sclerosing cholangitis, autoimmune hepatitis, and overlap in Utah children: epidemiology and natural history. Hepatology. 2013; 58(4):1392-400. [PubMed: 23686586]

85. Boberg KM, Aadland E, Jahnsen J, et al. Incidence and prevalence of primary biliary cirrhosis, primary sclerosing cholangitis, and autoimmune hepatitis in a Norwegian population. Scand J Gastroenterol. 1998; 33(1):99-103. [PubMed: 9489916]

86. Hurlburt KJ, McMahon BJ, Deubner H, et al. Prevalence of autoimmune liver disease in Alaska Natives. Am J Gastroenterol. 2002; 97(9):2402-7. [PubMed: 12358264]

87. Ngu JH, Bechly K, Chapman BA, et al. Population-based epidemiology study of autoimmune hepatitis: A disease of older women? J Gastroen Hepatol. 2010; 25(10):1681-6.

88. Myers RP, Shaheen AA, Fong A, et al. Epidemiology and natural history of primary biliary cirrhosis in a Canadian health region: a population-based study. Hepatology. 2009; 50(6):1884-92. [PubMed: 19821525]

89. Kim WR, Lindor KD, Locke GR 3rd, et al. Epidemiology and natural history of primary biliary cirrhosis in a US community. Gastroenterology. 2000; 119(6):1631-6. [PubMed: 11113084]

90. Inoue K, Hirohara J, Nakano T, et al. Prediction of prognosis of primary biliary cirrhosis in Japan. Liver. 1995; 15(2):70-7. [PubMed: 7791541]

91. Watson RG, Angus PW, Dewar M, et al. Low prevalence of primary biliary cirrhosis in Victoria, Australia. Melbourne Liver Group. Gut. 1995; 36(6):927-30. [PubMed: 7615286]

92. Ilyas JA, O’Mahony CA, Vierling JM. Liver transplantation in autoimmune liver diseases. Best Pract Res Clin Gastroenterol. 2011; 25(6):765-82. [PubMed: 22117641]

93. Kuiper EM, Hansen BE, Metselaar HJ, et al. Trends in liver transplantation for primary biliary cirrhosis in the Netherlands 1988-2008. BMC Gastroenterol. 2010; 10:144. [PubMed: 21172005]

94. Molodecky NA, Kareemi H, Parab R, et al. Incidence of primary sclerosing cholangitis: a systematic review and meta-analysis. Hepatology. 2011; 53(5):1590-9. [PubMed: 21351115] 
95. Toy E, Balasubramanian S, Selmi C, et al. The prevalence, incidence and natural history of primary sclerosing cholangitis in an ethnically diverse population. BMC Gastroenterol. 2011; 11:83. [PubMed: 21767410]

96. Eaton JE, Talwalkar JA, Lazaridis KN, et al. Pathogenesis of primary sclerosing cholangitis and advances in diagnosis and management. Gastroenterology. 2013; 145(3):521-36. [PubMed: 23827861] 


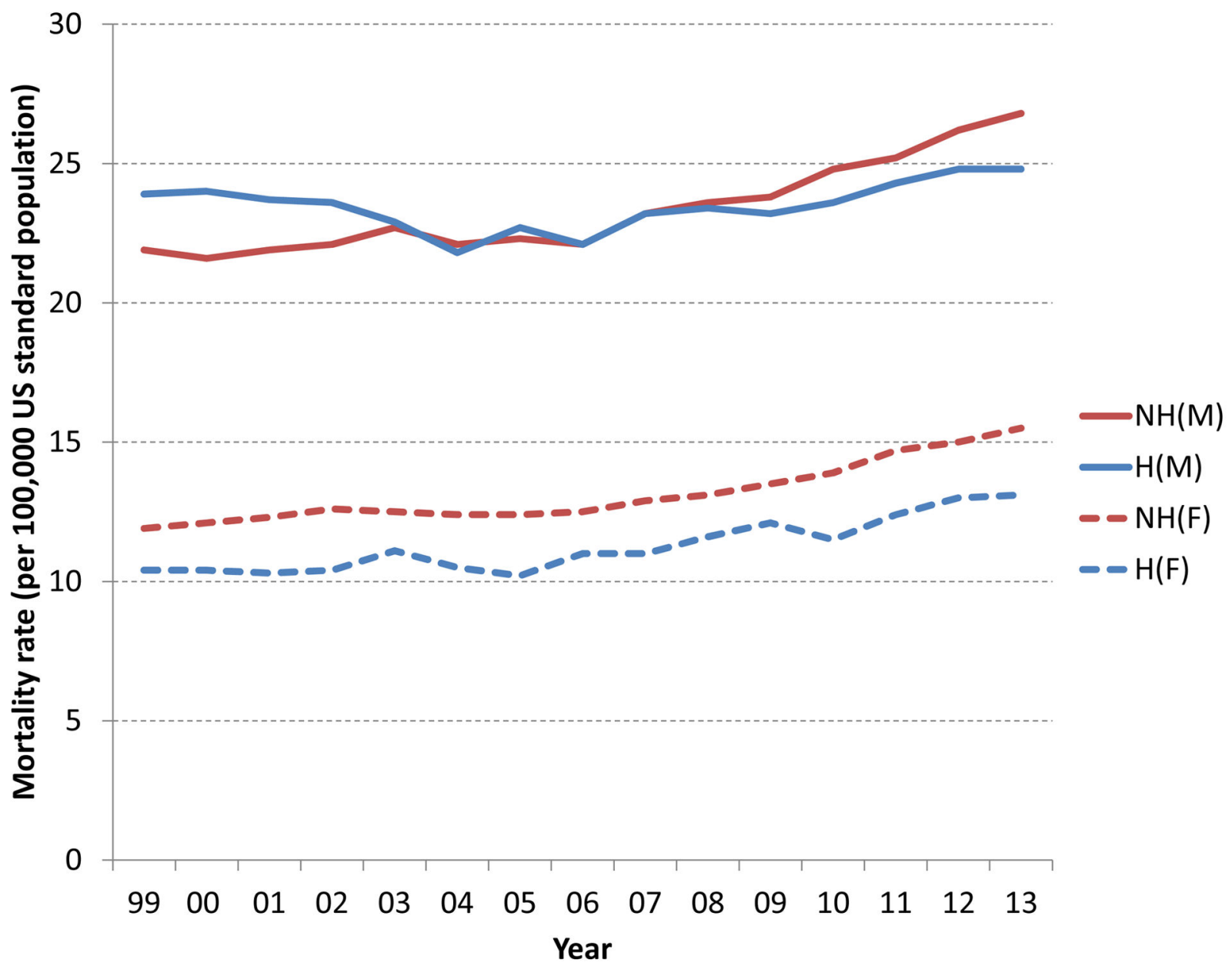

Figure 1.

Annual trends in mortality from liver disease by Hispanic ethnicity and gender in the US (deaths per 100,000 per year, adults $>25$ years of age)

Abbreviations: Non-Hispanic (NH), Hispanic (H), Male (M), Female (F) 


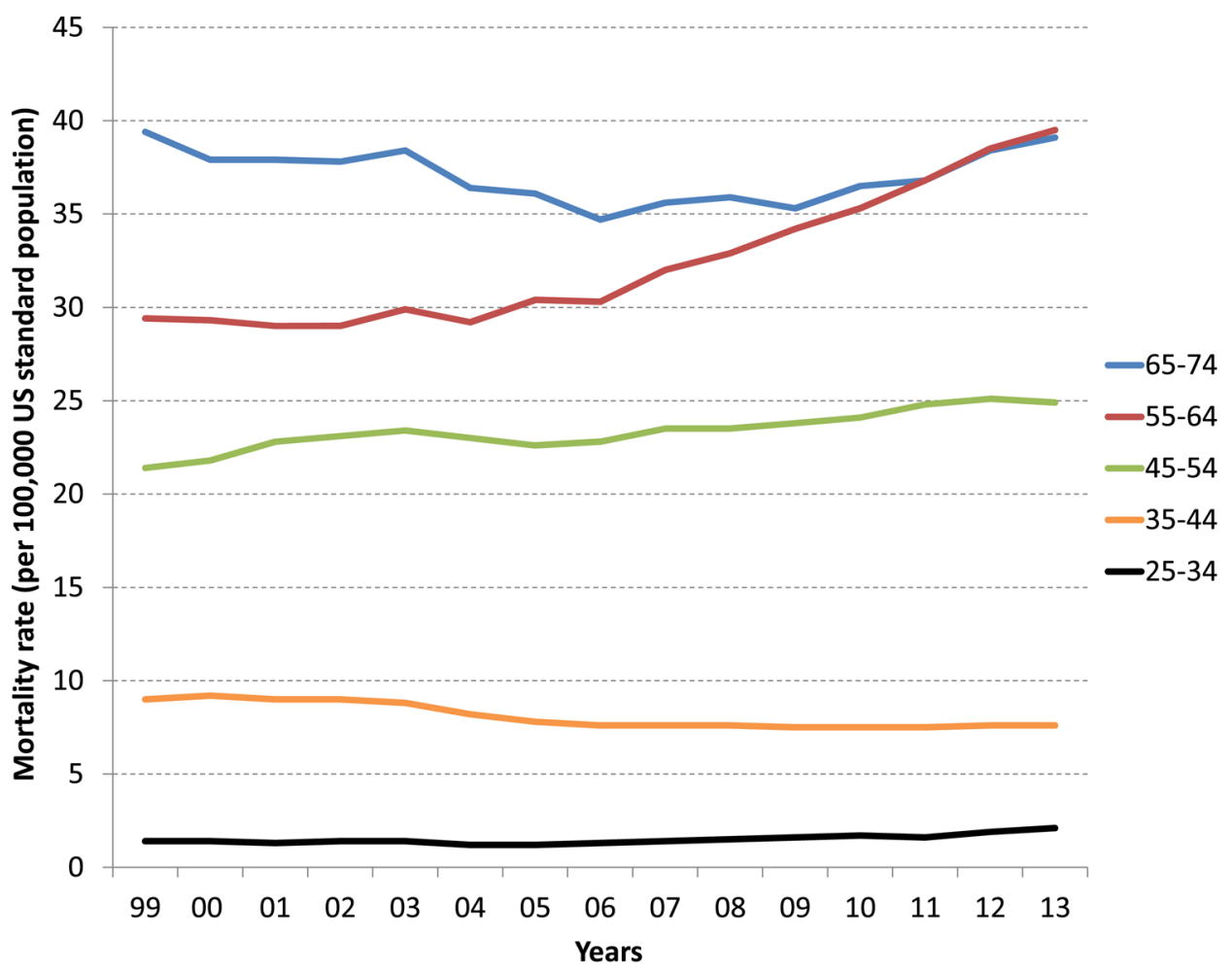

Figure 2.

Annual trends in mortality from liver disease by age group (deaths per 100,000 per year, adults $>25$ years of age) 


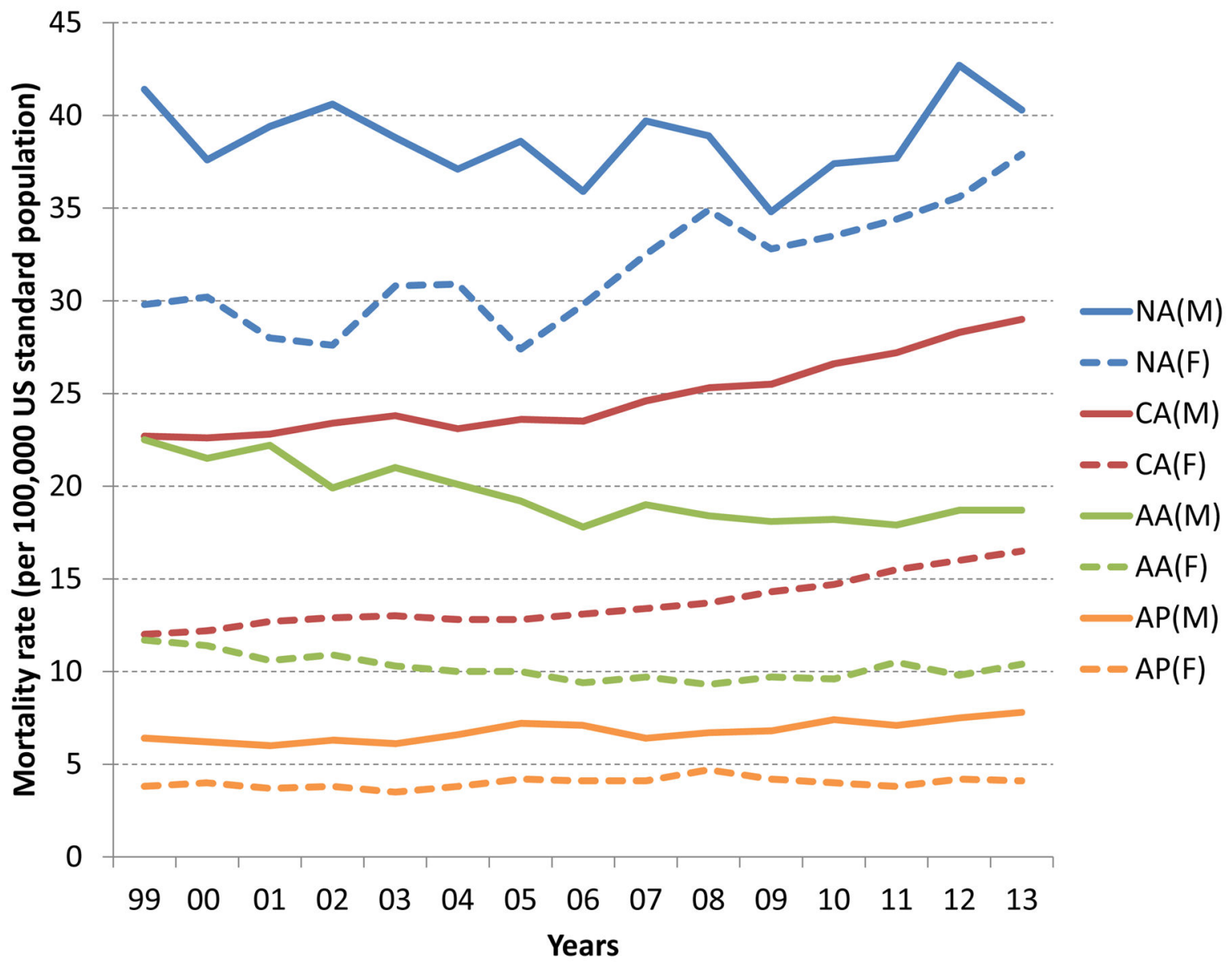

Figure 3.

Annual trends in mortality from liver disease by race and gender in the US (deaths per 100,000 per year, adults $>25$ years of age)

Abbreviations: Native American and Alaskan Native (NA), Caucasian (CA), African (AA), Asian-Pacific Islander (AP), Male (M), Female (F) 


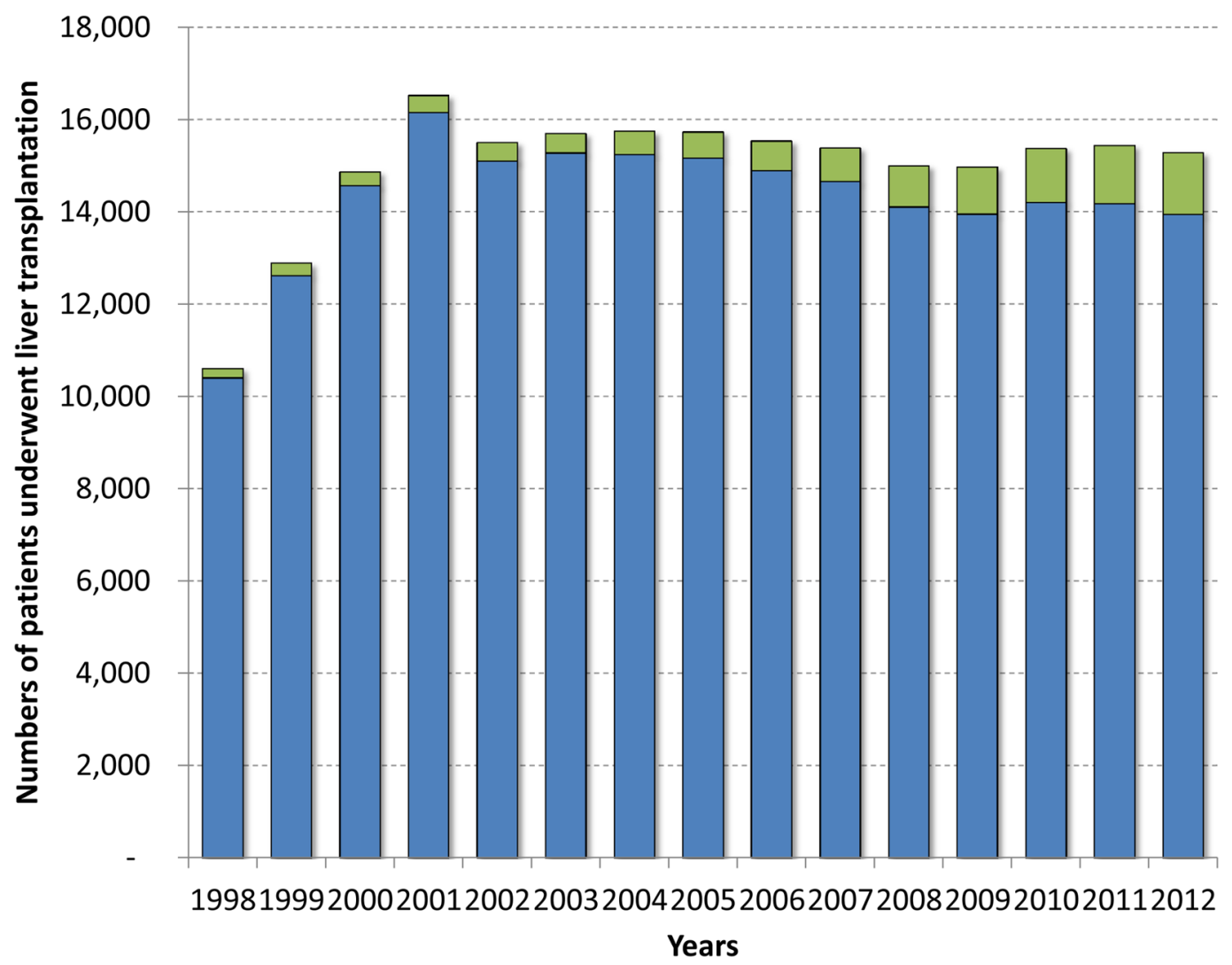

Figure 4.

Annual trends in the number of waitlist registrants for liver transplantation (number on December 31 of each year)

$\square$ Hepatocellular carcinoma indication Non- $\square$ HCC indication 


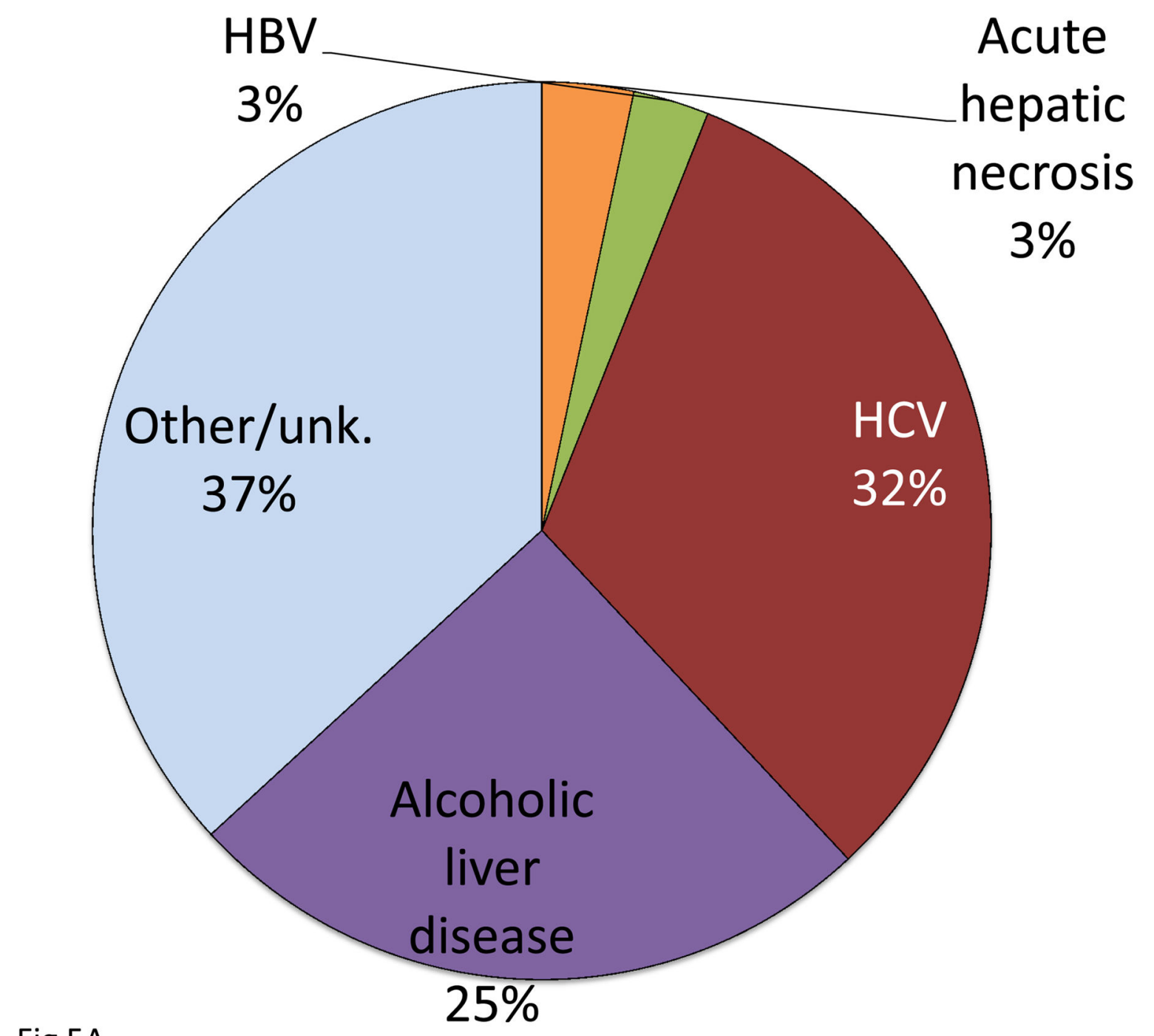

Fig 5A

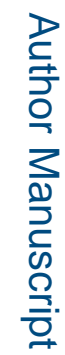




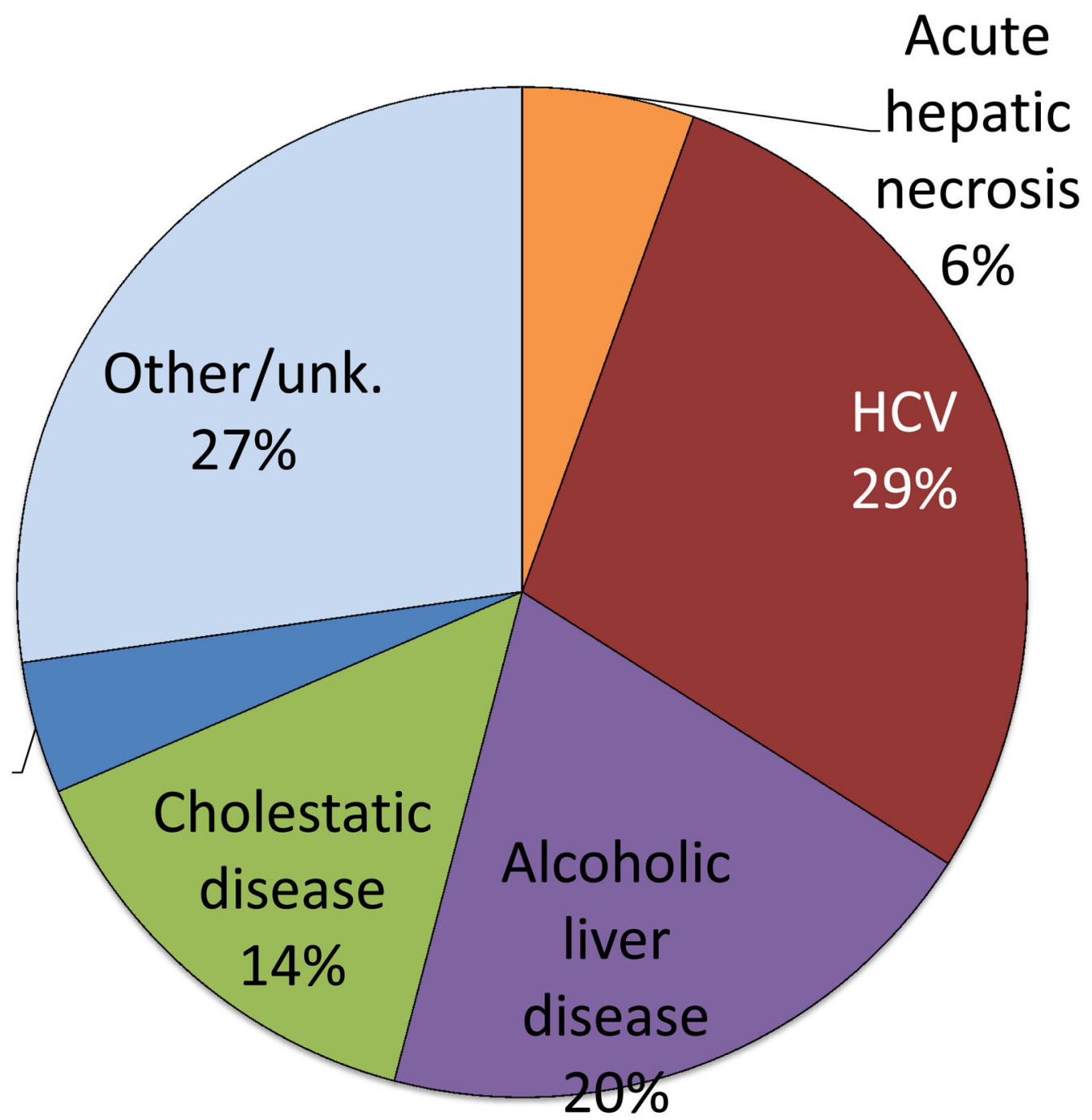

Figure 5.

Indication for liver transplantation

5(A): Indication at the time of waitlist registration

5(B): Indication at the time of transplantation 


\section{Table}

Summary table outlining the estimates of disease prevalence and diseases specific mortality rate

\begin{tabular}{|l|c|c|}
\hline Chronic liver diseases & Prevalence (per 100,000 individuals) & Mortality rate (deaths per 100,000 per year) \\
\hline Chronic Hepatitis C & $2,000-3,000^{11}$ & $4.6^{13}$ \\
\hline Alcoholic Liver Disease & $2,000-3,0000^{*}, 26$ & $7.2^{25}$ \\
\hline Nonalcoholic Fatty Liver Diseases & $6,000-35,000^{37}$ & $1.3-2.6^{42,43,46-49}$ \\
\hline Chronic Hepatitis B & $2,000-8,000^{60}$ & $0.6^{13}$ \\
\hline Hereditary Hemochromatosis & $3.9-6000^{* *, 68,69}$ & $1 \%$ of all liver transplantation ${ }^{\#, 70}$ \\
\hline Wilson Disease & $3^{72}$ & $1.5 \%$ of all liver transplantation ${ }^{\#,}, 4$ \\
\hline Alpha-1 antitrypsin deficiency & $20-33.3^{76-78}$ & $1 \%$ of all liver transplantation ${ }^{\#, 82,83}$ \\
\hline Primary Biliary Cirrhosis & $22.7-40.2^{88,89}$ & $12 \%$ of all liver transplantation ${ }^{\#, 92}$ \\
\hline Primary Sclerosing Cholangitis & $4.15^{95}$ & $8 \%$ of all liver transplantation ${ }^{\#, 92}$ \\
\hline Autoimmune Hepatitis & $16.9-42.9^{85-87}$ & $4 \%$ of all liver transplantation ${ }^{\#, 92}$ \\
\hline
\end{tabular}

These numbers were estimated from the reference no.23.

$* *$

The prevalence of hereditary hemochromatosis varied by ethnicity (lowest in Asians, highest in Northern European)

\# The population-based data for the mortality rates of these diseases are not available. Hence, we used the proportions of patients who were undergone liver transplantation for each disease as a surrogate marker of the mortality rate. 